\title{
Dietary habits and nutrient intake of school going adolescent girls
}

\author{
Rakhee Katiyar and Gurmeet Kaur
}

\begin{abstract}
A study on the dietary habits and nutrient intake of 400 school going adolescent girls was conducted at Kanpur Nagar selected purposively of Kanpur district during 2017-2018. All the girls within the age group of 13-19 years studying in $8^{\text {th }}$ to $12^{\text {th }}$ standards were selected from 10 schools of Kanpur. The dietary habits and food frequencies of girls was assessed by using questionnaire method. Information about food consumption pattern was gathered through 24-hours diet recall method and their nutrient intake was calculated by using the values given in the nutritive value of Indian foods (Gopalan et al., 1989). The nutrient intake was compared with the RDA suggested by ICMR (2010). The results of the study revealed that about 31.5 per cent of adolescent girls skipped their breakfast, 22.0 per cent their lunch and 11 per cent their dinner. Water intake pattern indicated that about 28.7 per cent of girls had only 2-4 glasses in a day. More than half $(58.7 \%)$ were found to have water with their meals followed by 18.7 per cent preferred tea or coffee or juice with their meals. While having food, 48.3 per cent girls were busy in watching television. About 74.5 per cent girls were nonvegetarian and 40.5 per cent were found to have fast foods two to three times in a week. The per cent adequacy of energy, protein, calcium, iron, vitamin A, folic acid and zinc varied from 24-79 whereas the per cent adequacy of fats, 145 was found to be higher in the girls than the RDA. The results of the study showed that there is immense need to improve the dietary habits of school going adolescent girls to make their life nutritionally sound.
\end{abstract}

Key Words : Adolescent, Dietary habits, Food frequencies, Nutritive value, Recommended dietary allowances

How to cite this article : Katiyar, Rakhee and Kaur, Gurmeet (2019). Dietary habits and nutrient intake of school going adolescent girls. Food Sci. Res. J., 10(1): 84-93, DOI : 10.15740/HAS/FSRJ/10.1/84-93. Copyright@ 2019: Hind Agri-Horticultural Society. 